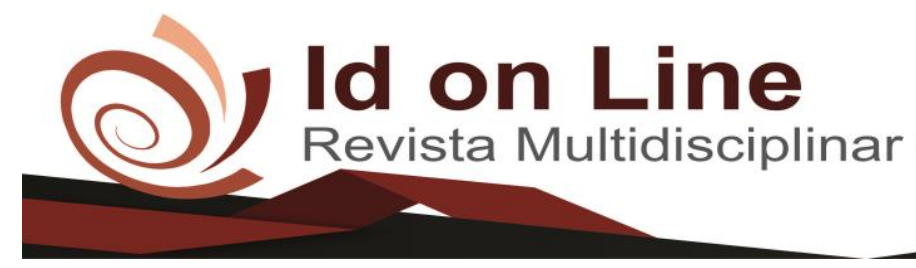

DOI: 10.14295/idonline.v13i48.2268

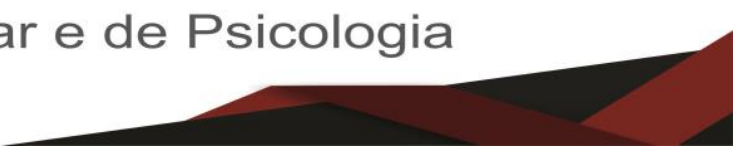

Relato de Experiência

\title{
Relato sobre o Programa de Residência Pedagógica: Um olhar sobre a Formação Docente
}

\author{
Sheila Maria Santos Gonçalves ${ }^{1}$; João Felix da Silva² ; Maria das Graças Bento ${ }^{3}$
}

\begin{abstract}
Resumo: O presente artigo tem por finalidade apresentar o objetivo do Programa de Residência Pedagógica e uma das ações que integram a política nacional de formação de professores e tem por objetivo induzir o aperfeiçoamento da formação prática nos cursos de licenciatura, promovendo a imersão do estudante de Licenciatura em Pedagogia na escola básica. A residência pedagógica, articulada aos demais programas do capes, premissas básicas o entendimento de que a formação de professores nos cursos de pedagogia deve assegurar seus egressos, habilidades e competências que lhes permita realizar um ensino de qualidade nas escolas de Educação Básica. O processo de formação realizado no espaço da escola indica para o nosso desenvolvimento profissional. Com o estudo desta iniciativa pode servir de base para a formação de experiências inovadoras na formação inicial de professores da Escola Básica. O programa de residência pedagógica vem buscando o aprimoramento da formação docente por meio da necessária articulação entre o que os alunos aprendem na universidade e o que experimentam na prática da residência, considerando que justamente um dos aspectos mais importantes em relação à formação docente é proporcionar ao aluno de pedagogia oportunidades de relacionar teoria e prática docente. A busca por formação, contribuí para que os professores se adaptem às diversas configurações sociais, culturais e educacionais, que processa, nesse novo contexto histórico, como o objetivo de se fortalecerem para que permeiem a educação dos cidadãos críticos e convictos de que é possível viver e fazer melhor na sociedade brasileira. Ressalta-se, portanto, que o processo de formação docente adquirida de maneira inicial e continuada oferecendo possibilidades aos professores de aperfeiçoarem os seus conhecimentos e disposições para exercer em sua profissão, o que reforça a ideia de que ambas as informações são importantes, pois integram diferentes oportunidades de crescimento e desenvolvimento profissional e pessoal.
\end{abstract}

Palavras-chave: Programa de residência pedagógica e formação docente.

\section{Report on the Pedagogical Residence Program: A look at the Teacher Education}

\begin{abstract}
This article aims to present the objective of the Pedagogical Residency Program and one of the actions that integrate the national teacher training policy and aims to induce the improvement of practical training in undergraduate courses, promoting the immersion of the undergraduate student in Pedagogy in elementary school. The pedagogical residency, articulated to the other capes programs, basic premises the understanding that the formation of teachers in the pedagogy courses must assure their graduates, abilities and competences that allow them to realize a quality teaching in the schools of Basic Education. The training process carried out in the school space indicates for our professional development. With the study of this initiative can serve as a basis for the formation of innovative experiences in the initial formation of elementary school teachers. The pedagogical residency program has been seeking to improve teacher education through the necessary articulation between what students learn at university and what they experience in residency practice, considering that one of the most important aspects in relation to teacher education is to provide pedagogy student opportunities to relate teaching theory and practice. The search for training contributed for teachers to adapt to the various social, cultural and educational configurations, which processes, in this new historical context, as the goal of strengthening themselves to permeate the education of critical citizens and convinced that it is possible to live and do better in Brazilian
\end{abstract}

\footnotetext{
${ }^{1}$ Graduanda em pedagogia, Faculdade de Ciências Humanas do Sertão Central - FACHUSC, ss1711708@gmail.com;

${ }^{2}$ Psicopedagogo, Faculdades Integradas de Patos - FIP, joaofelixserrita@ hotmail.com;

${ }_{3}^{3}$ Mestre, Universidade Católica de Pernambuco, professoragracabento@ hotmail.com.

670 Id on Line Rev. Mult. Psic. V.13, N. 48 p. 670-683, Dezembro/2019 - ISSN 1981-1179 Edição eletrônica em htttp://idonline.emnuvens.com.br/id
} 
society. Therefore, it is noteworthy that the process of teacher training acquired initially and continuously offering possibilities for teachers to improve their knowledge and dispositions to exercise in their profession, which reinforces the idea that both information is important, because integrate different opportunities for professional and personal growth and development.

Keywords: Pedagogical residency program and teacher training.

\section{Introdução}

Cada relato neste artigo é fruto do período de residência pedagógica e como experiência fundamental para a formação de qualidade de futuros professores, já que ele possibilita a articulação entre a teoria e a prática social da profissão docente. Esse espaço, se bem planejado, tem objetivos claros e sendo contemplado em uma estrutura curricular que possibilite essa articulação seja feita, dá ao estudante a vigência da profissão e oportunidade para que a teoria possa ser significada, além de desenvolver importantes habilidades de um professor reflexivo.

Observa-se nas práticas correntes, que há um grande distanciamento entre os discursos acadêmicos e a ação realizada nas escolas, sendo esse um importante obstáculo a ser ultrapassado na estrutura e organização dos cursos de formação inicial.

Essa etapa é de grande relevância, pois permitiu o contato direto com a instituição de ensino docente e discente, além do mais a observação e prática possibilita a reflexão sobre as práticas existentes no sistema educacional brasileiro em paralelo com os conhecimentos adquiridos durante o curso de pedagogia pela Faculdade de Ciências Humanas do Sertão Central-FACHUSC.

A formação de professores deve ser um processo contínuo e permanente, confirmado na fala do professor: "Não é uma tarefa de um dia para o outro. A formação continuada é devagar e todo dia", esse processo continuado de professores.

Justifica-se a realização desse artigo, pois ele descreve as práticas e as vivencias na prática e sua relação com as teorias e outra no conhecimento, fortalecendo o processo acadêmico e profissional a partir dessa residência pedagógica. 


\section{Fundamentação Teórica}

A concepção do curso de pedagogia busca aproximar a teoria da prática em diversos momentos e isso é vivenciado na escrita do projeto pedagógico, quanto nas próprias escolhas dos livros didáticos e na organização do currículo. Sendo assim, o próprio Programa de Residência Pedagógica está inserido em um contexto, em outros aspectos favorecem sua realização e ampliam sua potencialidade.

A partir da segunda metade do curso de pedagogia ( $5^{\circ}$ semestre), começa a ser vivenciado pelos estudantes do Programa de Residência Pedagógica - PRP, que tem a função de aproximar a prática profissional da formação inicial. Mais do que isso, o PRP, propicia a vivência de modo articulado com algumas escolas municipais de Penaforte - Ceará, que são parceiras na função de formar os futuros professores.

Além dos benefícios aos estudantes, o PRP propõe a aproximação da formação inicial e continuada, já que as escolas que participam do programa, como contra partida, participam de momentos de formação continuada desenvolvidos pelos professores preceptores e pela própria universidade.

Segundo projeto pedagógico, o objetivo deste programa é:

(...) possibilitar a aprendizagem prática "em situação", ou seja, a partir da realidade, tomando os eventos e aspectos dificultados para a prática pedagógica do professor e da escola como fontes de aprendizado, uma vez que esses aspectos e eventos são tomados como objeto de estudo e reflexão pelos residentes, orientados por seus preceptores e que resultam em matéria a ser tratada também no âmbito da escola, a partir do diálogo com professor formador e gestores que acolhem o residente na escola. (UNIFESP, 2006, p. 31).

O período de residência permitiu ampliar o conhecimento a respeito das atividades administrativas e pedagógicas nesse período de aproximação entre o estudo do professor no seu cotidiano, tendo-o como ser histórico e socialmente contexto, pode auxiliar na definição de uma nova ordem pedagógica e na intervenção da realidade no que se refere a sua prática e a sua formação profissional. Discuti-la durante o período de formação inicial de modo a construir bases teóricas que embasam em uma ação futura e um dos pontos altos oportunizados para os estudantes do curso de pedagogia da FACHUSC. A prática profissional é o eixo norteador do programa e na intervenção da realidade no que se refere a sua prática e a sua formação. 
Pode-se dizer que o motor que anima e dá sentido tanto na pedagogia, como nas demais licenciaturas, em busca da relação continua possível e necessária entre os estudantes teoria e a prática cotidiana, o residente deverá relacionar-se adequadamente com a escola e /ou outra instituição educacional, buscando compreendê-las em suas relações internas, reconhecendo-a em seu contexto específico. Importa analisar o quê acontece, como, por que, onde, com quem e quando acontecem em determinados situações buscando um novo sentido diante do que está sendo observado e apreendido no processo de junto à realidade observada. (CALDERANO, 2012, p. 251)

A formação do discente do curso de pedagogia por meio do desenvolvimento do projeto que fortalece o campo da prática e conduzem o licenciando a exercitar de formativa, a relação entre teoria e prática profissional docente, utilizando coleta de dados e metodologias: A prática, portanto é um "solo fértil" para que o docente encare/assuma o desafio da pesquisa, onde o objetivo de investigação faça parte do seu cenário pedagógico diário, permitindo-lhe refletir e melhor atuar sobre ele dessa forma, teremos como afirmar, segundo Estebame Zaccur (2002:22) "uma práxis como resultada da síntese da teoria e da prática".

$\mathrm{Na}$ sua construção de um campo da teoria que investiga a formação, e o trabalho a profissionalização docente tem avançado nos últimos anos, e realizando incursões por diversos campos, dentre eles a epistemologia da prática, sendo a questão dos saberes e das experiências um dos aspectos investigados nos estudos sobre constituição de identidade profissional docente.

Nos mais bem-sucedidos exemplos de gestão escolar participativa observaram-se que os diretores dedicam uma quantidade considerável de tempo à capacitação profissional e ao desenvolvimento de um sistema de acompanhamento escolar e experiência pedagógica pela reflexão e ações.

Aproximação entre a teoria e a prática é foco de discussão de muitos estudiosos, que defendem uma maior articulação e integração entre universidade e escola, com uma busca de imersão durante o processo de formação inicial sair do isolamento dos ambientes formativos da universidade e escola, foi que ambas estão embutidas de gnose igualmente importantes e complementares. O ensino através do estudo desta parceria é composto por uma sequência de tarefas como planejamento, discussão e análise que tem por objetivo conhecer as dificuldades dos alunos, os aspectos positivos de cada um e buscar de forma concreta o avanço do aluno, para que ele possa demonstrar seu conhecimento. É nesta parceria que a didática tem sua participação ativa, pois, sem a didática seríamos apenas reprodutores. Libâneo (2017) diz,:

O ensino consiste no planejamento, organização, direção e avaliação da atividade didática, concretizando as tarefas da instrução; o ensino inclui tanto o trabalho do professor (magistério) como a direção da atividade de estudo dos alunos. Tanto a 
instrução como o ensino se modificam em decorrência da sua necessária ligação com o desenvolvimento da sociedade e com as condições reais em que ocorre o trabalho docente. Nessa ligação é que a Didática se fundamenta para formular diretrizes orientadoras do processo de ensino (LIBÂNEO, 2017, p.53).

A residência pedagógica tem papel fundamental na formação inicial de professores, pois é o momento em que o graduando pode se apropriar de uma realidade que antes fazia parte somente dos assuntos abordados em debates. Zabalza (2014, p. 32) reforça essa característica dizendo que o estágio tem como "principal objetivo propiciar que os estagiários vivenciem e pratiquem o que lhes é ensinado teoricamente em sala de aula (...)”, auxiliando na construção da identidade profissional revelando assim “(...) o melhor conhecimento de si mesmo e de seus pontos fortes e fracos em relação à profissão escolhida.”.

Os objetivos do estágio são propostos como:

- Aplicar seus conhecimentos e habilidades em contextos práticos.

- Compreender melhor a prática real de sua profissão.

- Avaliar o próprio progresso e identificar aquelas áreas em que seria necessário um desenvolvimento pessoal e/ou profissional mais profundo. (DARESH, 1990 apud ZABALZA, 2014 p. 47).

A residência pedagógica proposta pela FACHUSC parte do princípio de imersão dos alunos durante um período consecutivo em todas as atividades desenvolvidas na escola que lhe é designado pelo professor e preceptor.

(...) a formação centrada na escola envolve estratégias, empregadas conjuntamente pelos formadores e pelos professores para dirigir os programas de formação de modo que respondam às necessidades definidas da escola e para elevar a qualidade de ensino e aprendizagem em sala de aula nas escolas. (IMBERNÓN, 2010, p. 85)

A formação de professores deve ser concebida num contínuo entre a formação inicial e a formação continuada. Na concretização do Programa de Residência Pedagógica, é possível vislumbrar essa perspectiva defendida por Marcelo (1992) uma vez que as ações de formação continuada ainda estão em praticas nas escolas abrangem a problemática trazida tanto pelos residentes quanto no contato dos preceptores com as escolas.

A diferença central encontra na finalidade: ARP e parte da formação inicial e
essencialmente de uma aprendizagem que acompanha a graduação e ganha sentido de
especialização profissional. Aproximadamente está na imersão do estudante no
processo de contato sistemático temporário com as práticas profissionais reais no caso
como professores e gestores educacionais (formadores) que atuam no contexto das
escolas públicas. (UNIFES, 2006, p. 48) 
Busca-se com a imersão durante o processo de formação inicial sair do isolamento dos ambientes formativos da universidade e escola, aproximando as culturas destes locais e identificando saídas criativas para a formação docente. O PRP se propõe a aproximar estas duas realidades.

O projeto é um vinculo entre a teoria e a prática, no processo de ensino e aprendizagem juntamente com o apoio da universidade e a escola campo, buscando sempre aprimorar o conhecimento dos discentes, ressaltando questões políticas que reafirma o compromisso com a educação pública de boa qualidade, com o propósito de desenvolver um educador comprometido e ético, mesmo com todas as circunstâncias dos desafios enfrentados em sala, construírem métodos que superam os limites.

(...) Atividade que possibilitem o conhecimento do trabalho docente, das ações docentes nas instituições, a fim de compreendê-las em historicidades, identificar seus resultados, os impasses que apresentam às dificuldades. (PIMENTA E LIMA, 2011, p. 55).

Nesse sentido há um interesse no programa residência de induzir a forma e o conteúdo das atividades e reflexões sobre o trabalho docente verticalizados em duas ações: Vincular as ações do residente na aprendizagem dispostas na BNCC; enfatizar atividades práticas, entendidas como imersão na sala de aula centrando o ato pedagógico no fazer metodológico curricular. "Ser professor passa a pressupor um profissional atualizado, estudioso e dinâmico. Ensinar consiste mais em um ofício artesanal que implica a posse de um saber duradouro." (SOUZA, 1996, p. 190).

O programa de residência pedagógica vem buscando o aprimoramento da formação docente por meio da necessária articulação entre o que os alunos aprendem na universidade e o que experimentam na prática da residência, considerando que justamente um dos aspectos mais importantes em relação à formação docente é proporcionar ao aluno de pedagogia oportunidades para que desenvolva a capacidade de relacionar teoria e prática docente.

Vários autores já destacaram a necessidade de que o professor reflita sobre sua experiência, considerando que apenas na formação aconteça no exercício da profissão e que muitas aprendizagens apenas se dão na prática cotidiana da escola. Não há como desenvolver certas habilidades apenas pelo viés teórico já que, na atuação docente faz-se necessário tomar decisões, resolver problemas imprevisíveis da prática cotidiana, enfim, articular conhecimentos 
e habilidades para atingir os objetivos propostos. Para o autor, quando a aprendizagem da profissão se dá no seu exercício, aproximando o conhecimento prático dos professores das escolas e a supervisão da universidade, a articulação entre saberes de naturezas diversas acontece inevitavelmente. $\mathrm{O}$ desejo de encontrar soluções para casos concretos mobiliza saberes teóricos, que são imprescindíveis para sua resolução, com a sua formação que garante a sua experiência a profissional e pessoal.

A aproximação entre a teoria e a prática é foco de discussão de muitos estudiosos, que defendem uma maior articulação e integração entre a universidade e a escola, já que ambas estão embutidas de saberes importantes são complementares. Há algumas características comuns nas propostas, destacamos a de que a residência docente se estabeleceria como uma fase posterior à formação inicial do profissional habilitado para atuar na docência da educação básica, no primeiro projeto de modo obrigatório para o ingresso na carreira e nos demais como forma pontuação nos concursos e também de atualização profissional. A nomenclatura utilizada nos três projetos citados: residência educacional, residência pedagógica e residência docente e a forma que são apresentados mostram o campo de fragilidade teórico-metodológico e pouco aprofundamento sobre a perspectiva do conceito. Vinculam a residência ao formato da experiência da formação médica. Como programa de formação continuada, sem adentrar nas especificidades da formação docente.

$\mathrm{Na}$ atuação docente, não basta conhecer muitas coisas, basta ter teorias e práticas para ser um bom professor, é necessário saber quando utilizar, como e acima de tudo, reelaborá-las constantemente para solucionar os problemas que são impostos cotidianamente na ação docente.

\footnotetext{
(...) A residência pedagógica consiste na imersão planejada e sistemática do aluno de licenciatura em ambiente escolar visando à vivência e experimentação de situações concretas do cotidiano escolar e da sala de aula que depois servirão de objeto de reflexão sobre a articulação a refletir e avaliar sobre sua pratica e relação com a profissionalização do docente escolar, para registro em relatório contribuindo para a avaliação de socialização de sua experiência como residente. (EDITAL DO CAPES, $08 ; 2018)$
}

A questão da concepção da residência na formação de professores remete a fim terceiro elemento de análise do edital Capes 06/2018, que é induzir a reformulação do residente. Por que se formular a residência? Levantemos duas questões que perpassam a resposta e essa questão. Em primeiro lugar, trata-se da questão da relação teoria e prática considerando que as 
pesquisas de Pimenta e Lima (2011), apontam que os residentes nas licenciaturas podem ser o espaço da prática na formação inserida.

Todo caminho da gente é resvalos, mas também cair não prejudica demais, a gente levanta, a gente sabe, a gente volta o correr da vida, embrulha tudo, a vida é assim, esquenta, esfria, aperta e daí afrouxa, sossega e depois desinquieta, o que ela quer da gente é coragem, ser capaz de ficar alegre, de resistir. (ROSA, João Guimarães, 2011)

Discuti-las durante o período de formação inicial de modo a construir bases teóricas que embasam em uma ação futura e um dos pontos altos são oportunizados para os estudantes do curso de pedagogia da FACHUSC. A prática profissional é o eixo norteador do programa de residência pedagógica. Segundo o projeto político pedagógico, o estudo do professor, no seu cotidiano, tendo-o como ser histórico e social no seu contexto para auxiliar na definição de uma nova ordem pedagógica e na intervenção da realidade no que se refere a sua prática e sua formação.

\begin{abstract}
A formação de professores é área de conhecimentos, investigação e de propostas teóricas e práticas que, no âmbito da didática e da organização escolar, estuda os processos, através dos quais os individualmente ou em equipe, em experiências de aprendizagem através dos quais adquiriram ou melhoram seus conhecimentos, competências e disposições e que lhes permitem intervir profissionalmente no desenvolvimento do seu ensino, do currículo e da escola, com objetivo de melhorar a qualidade da educação que os alunos recebem. (MARCELO GARCIA, 1889, p. 26)
\end{abstract}

$\mathrm{Na}$ construção de um campo teórico que investiga a formação, o trabalho e a profissionalização docente tem avançado nos últimos anos realizando incursões por diversos campos, dentre eles a epistemologia da prática, sendo a questão dos saberes da experiência um dos aspectos investigados nos estudos sobre constituição de identidade profissional docente.

"Ser professor hoje é viver intensamente o seu tempo com consciência e sensibilidade. Não se pode imaginar um futuro para a humanidade sem educadores. Os educadores, numa visão emancipadora, não só transformam a informação em conhecimento e em consciência crítica, mas também formam pessoas diante dos falsos pregadores da palavra, dos marqueteiros, eles são os verdadeiros "amantes" da sabedoria, os filósofos de que nos falava Sócrates, eles fazem fluir o saber, não o dado, a informação, o puro conhecimento, por que constroem sentido para a humanidade e buscam junto, mas produtivo e mais saudável para todos".

Considera a formação continuada de professores como uma preparação e emancipação profissional do docente para realizar de forma crítica e reflexiva, estratégia de ensino que 
potencializem a aprendizagem significativa nos discentes e um pensamento inovador e ativo para trabalhar em equipe com os professores.

\section{Metodologia}

Após análise da proposta do programa de Residência pedagógica surge à experiência dos preceptores na orientação aos residentes com a finalidade de passar conhecimentos sobre o ambiente escolar, tanto na fase de ambientação como imersão nas escolas campos. Esse conjunto de instrumentos pedagógicos, desenvolvidos no programa de residência pedagógica, faz a mediação entre a experiência, a reflexão, a ação, a formalização e a teorização, no sentido de articular os tempos e espaços de formação e fazer dialogar os saberes práticos e teóricos. Esta troca de experiências e o contato dos preceptores com as escolas, os professores formadores faz com que os residentes superem seus limites.

Durante todo o processo, a atuação do professor preceptor possui destaque, pois ele faz os primeiros contatos com os estudantes de cada equipe que vai para a escola campo e é quem orienta o as fases do programa, acompanhando o residente durante todo o percurso do programa. Antes de iniciar a imersão na escola, os estudantes participam de encontros pontuais com seus preceptores para discussão do programa de atividades, fazendo estudo dos componentes curriculares das unidades de ensino. Fazendo com que o residente compreenda a mediação entre a teoria e prática.

Nesse contexto, é notória a contribuição de Vygotsky (1981) quando ele afirma que as relações humanas são sempre mediadas pelo meio sociais e pelos instrumentos e signos que fazem parte das relações e dos contextos em que o homem está inserido. Desse modo:

\footnotetext{
A atividade prática do homem, portanto, se faz duplamente mediada: de uma parte, está mediada pelas ferramentas no sentido literal da palavra e, de outra parte, mediada pelas ferramentas no sentido figurado, pelas ferramentas do pensamento, pelos meios, com a ajuda dos quais se realiza a operação intelectual, ou seja, mediada com a ajuda das palavras. (VYGOTSKI, 1930/2006a, p. 165)
}

Nessa direção, convém informar a importância do preceptor como instrumento no dia a dia dos estudantes e na mediação do conhecimento em processos de aprendizagem e desenvolvimento dos graduandos. 
Os professores das escolas-campo transmitem a experiência faz com que o residente rompa a intimidade da sala de aula e da escola nos aspectos referentes aos seus espaços de trabalho para conviver com aprendizes que alteram suas rotinas em alguns momentos e que passam a integrá-las em outros. O contato inicial entre formador e residente é superado pela dinâmica do trabalho na classe e pela ação de colaboração que se desenvolve. Essa aproximação e interação são facilitadas pela imersão do residente que acompanha atentamente o trabalho do professor, na qualidade de colaborador aprendiz, que tem como objetivo elaborar estratégias juntamente com todos envolvidos, para que as dificuldades encontradas em sala de aula sejam minimizadas.

\section{Resultados e Discussão}

Para a construção desse artigo optou-se pelo relato descritivo em paralelo com análise de bibliografias vigentes e a análise do documento do programa de residência e documento do projeto pedagógico do curso de pedagogia $\mathrm{O}$ artigo foi desenvolvido com êxito a partir de preenchimento de fichamento das fichas podendo analisar a realidade escolar.

No caso do PRP, implantado desde 2018, os resultados explicitaram temas relacionados à propostas curriculares dos cursos de licenciaturas da FACHUSC, e mais recentemente a contribuição da parceria com o programa residência pedagógica com continuidade da formação possibilitando a reflexão/avaliação da proposta do curso de licenciatura em pedagogia com ênfase no programa de residência pedagógica.

Os resultados que orientaram a elaboração das atuais propostas promoveu a convocação de comissões com objetivo de estudo e elaboração de novas propostas a luz dos conhecimentos legais, dos programas e análise de resultado das parcerias entre PRP, programa residência e a escola básica.

Esse Programa de Residência Pedagógica está contribuindo e nomeando no projeto político pedagógico na contrapartida da universidade para escolas participantes, carrega em si aspectos, diferencia da proposta do PRP.

Esta ação tem um potencial, transforma não só no espaço de aprendizagem do residente, mas também na educação que é oferecida nas escolas municipais de Penaforte -CE, que participam do programa.

679 Id on Line Rev. Mult. Psic. V.13, N. 48 p. 670-683, Dezembro/2019 - ISSN 1981-1179 Edição eletrônica em http://idonline.emnuvens.com.br/id 
Além disso, aproximam as experiências de formação inicial e continuada, atribuindo peso equivalente as aprendizagens que se dão nesse momento no programa de residência.

É de fundamental importância esclarecer que a teoria e a prática devem caminhar juntas na mesma direção e não serem consideradas uma consequência da outra. Pimentel (2014) salienta que, é necessário que os conhecimentos teóricos tenham sentido e significado para que se possa perceber a relação entre a teoria e as ações cotidianas.

O programa residência pedagógica por tanto aparece como uma ideia que é na prática que o estudante de licenciatura tem a oportunidade de conhecer a sua área de atuação Futura, e entrar em contato com o fenômeno de vivenciar a realidade de sala de aula. É o momento em que os graduandos realizam na escola campo uma autorreflexão sobre sua área de atuação, tal perspectiva fragmentada a unidade teoria e prática e coloca na prática como concepção utilitária da formação de professores. Por meio do programa é possível perceber a concepção de educação e ver as relações de existentes dentro da educação básica.

Neste contexto foi possível perceber que o professor da escola campo tem a consciência da importância do trabalho coletivo, de trocar experiências, de auxiliar o residente na sua formação, pois um aprende com o outro num sistema de cooperação. O trabalho na sala de aula na fase de imersão tem como ponto de partida a discussão coletiva de um trabalho que começa com a realidade do aluno e desta forma o residente percebe que o professor não dever ser técnico, mas dinâmico, deve ser dotado de conhecimentos, habilidades e atitudes para crescer a cada dia de forma reflexiva e investigadora, superando dificuldades e desafios do contexto escolar.

O programa de residência pedagógica vem buscando aprimoramento na formação docente por meio de estratégias inovadoras, o mesmo articula relação entre o que os alunos aprendem na universidade e que experimentam na prática da residência, considerado justamente os aspectos mais importantes em relação à formação docente e teoria, deste modo o aluno de pedagogia tem a oportunidade de desenvolver a capacidade de relacionar a teoria e a prática docente. 


\section{Conclusões}

Esse estudo teve como objetivo a análise concebida e concretizada a relação entre a universidade e escola básica no programa de residência pedagógica, análise de dados: A análise do documento do programa de residência e documento do projeto pedagógico do curso de pedagogia, esses dois instrumentos foram de fundamental importância, e foram utilizados de maneira complementar para análise dos dados coletados, bem sucedida que a próxima entre os espaços formativos da escola e da universidade na formação inicial de professores em pedagogia.

A organização do Programa de Residência Pedagógica, regulamentada por um programa de residência entre a FACHUSC e a CAPES, permitindo que as ações ocorram de modo organizado e que o programa vai além de uma simples aproximação, legitimando e formalizando a parceria entre ambas. $\mathrm{O}$ estabelecimento do acordo no programa de residência revelou-se um avanço na formação dos futuros professores, uma vez que ele delega a escola, ações que apenas podem acontecer no espaço real de prática profissional. O programa de residência pedagógica vem buscando o aprimoramento de formação docente por meio da necessária articulação entre o que os alunos aprendem na universidade e o que experimentam a prática da residência, considerando que justamente um dos aspectos mais importantes do conhecimento da prática do licenciado. Portanto, a residência pedagógica é idealizada com o propósito de mostrar ao residente um campo de conhecimento amplo, composto por diferentes realidades.

No programa de residência pedagógica, algumas estratégias adotadas intentam concretizar a aproximação entre a universidade da escola. Certamente revelam-se certeiras em seu planejamento, e segundo a fala dos professores, é possível identificar algumas delas: a ida dos professores da universidade nas escolas, o acompanhamento dos preceptores e um grupo reduzido de alunos e a produção de trabalhos que desafiam olhar do residente para além dos aspectos teóricos e práticos considerando de forma em destaque na sua formação profissional.

Neste contexto o programa residência pedagógica exerce um papel fundamental na qualificação da educação, o mesmo aproxima teoria da prática, ou seja, fazendo com que os graduandos vão até a escola campo, todos que estão envolvidos no processo adquiram conhecimento por meio da troca de experiências. 
Por tudo descrito é notório que o programa residência pedagógica no curso de pedagogia da FACHUSC, é sem dúvida uma experiência modelo, que pode servir de referência para outras instituições, e inclusive, servir de base para a formulação de políticas públicas de qualificação de professores.

\section{Referências}

BRASIL. Ministério da Educação. Resolução CNE/CP n. 1/2006. Institui Diretrizes Curriculares para o Curso de Graduação em Pedagogia, licenciatura.

BRASIL. Ministério da Educação. Resolução CNE/CP 1, de 18 de fevereiro de 2002a. Diário Oficial da União, Brasília, 4 de março de 2002. Seção 1, p. 8.

BRASIL. Ministério da Educação. Resolução CNE/CP 2, de 19 de fevereiro de 2002b. Diário Oficial da União, Brasília, 4 de março de 2002. Seção 1, p. 9.

CALDERANO. M da A. - O estágio curricular e os cursos de formação de professores: Desafios de uma proposta orgânica. In: CALDERANO, M. da A.Org (Estágio Curricular: Concepções, Reflexões teórico-prático e Proposições. Juiz de Fora. Programa Residência Pedagógica e a Escola Básica.

GARCIA, Marcelo Carlos - Formação de Professores para uma mudança educativa. Porto: Porto Editora 1989.

IMBERNÓN. F - Formação continuada de Professores. Porto Alegre. Artmed 2010.

Libâneo, J. C. (2017). Didática. Cortez Editora.

ROSA, João Guimarães - Grande Sertão: Veredas. $19^{\mathrm{a}}$ Ed. Rio de Janeiro: Nova Fronteira, 2001, $624 \mathrm{p}$.

PIMENTA, Selma. GARRIDO, Lima, SOCORRO, Maria - Estágio é docência. $6^{\mathrm{a}}$ Ed. São Paulo: Cortez, 2011.

PIMENTEL, Edna Furukawa. A epistemologia e a formação docente: reflexões preliminares. In: RAMALHO, Betânia Leite; NUNES, Claudio Pinto; CRUSOÉ, Nilma Margarida de Castro (org.). Formação para a docência profissional: saber e práticas pedagógicas. Brasília: Liber Livro, 2014. p. 15-38

UNIFESP - Plano Pedagógico do Curso de Pedagogia. São Paulo 2006.

Disponível Em: <HTTP.humanas.unifesp.br/home/índex.php/cursosdegraduacao/2001. 
VYGOTSKY, Lev Semyonovich. Desarrollo de las funciones psíquicas superiores en la edad de transicion. in 1. s. Vygotsky, obras escogidas iv: Paidología del adolescente. Madrid: Machado Libros, Tomo IV 1930/2006 ${ }^{\text {a }}$

ZABALZA, M. A. O estágio e as práticas em contextos profissionais na formação universitária. São Paulo: Cortez, 2014.

\section{Como citar este artigo (Formato ABNT):}

GONÇALVES, Sheila Maria Santos; SILVA, João Felix da; BENTO, Maria das Graças. Relato sobre o Programa de Residência Pedagógica: Um olhar sobre a Formação Docente. Id on Line Rev.Mult. Psic., Dezembro/2019, vol.13, n.48, p. 670-683. ISSN: 1981-1179.

Recebido: $26 / 11 / 2019$

Aceito: 29/11/2019 